\title{
Ammonium nitrate evaporation and nitric acid condensation in DMT CCN counters
}

\author{
S. Romakkaniemi ${ }^{1,2}$, A. Jaatinen ${ }^{1}$, A. Laaksonen ${ }^{1,3}$, A. Nenes ${ }^{4,5}$, and T. Raatikainen ${ }^{3,4}$ \\ ${ }^{1}$ Department of Applied Physics, University of Eastern Finland, P.O. Box 1627, 70211 Kuopio, Finland \\ ${ }^{2}$ Finnish Meteorological Institute, P.O. Box 1627, 70211 Kuopio, Finland \\ ${ }^{3}$ Finnish Meteorological Institute, P.O. Box 503, 00101 Helsinki, Finland \\ ${ }^{4}$ School of Earth and Atmospheric Sciences, Georgia Institute of Technology, Atlanta, Georgia, USA \\ ${ }^{5}$ School of Chemical and Biomolecular Engineering, Georgia Institute of Technology, Atlanta, Georgia, USA \\ Correspondence to: S. Romakkaniemi (sami.romakkaniemi@fmi.fi)
}

Received: 10 June 2013 - Published in Atmos. Meas. Tech. Discuss.: 13 September 2013

Revised: 12 March 2014 - Accepted: 1 April 2014 - Published: 20 May 2014

\begin{abstract}
The effect of inorganic semivolatile aerosol compounds on the cloud condensation nucleus $(\mathrm{CCN})$ activity of aerosol particles was studied by using a computational model for a DMT-CCN counter, a cloud parcel model for condensation kinetics and experiments to quantify the modelled results. Concentrations of water vapour and semivolatiles as well as aerosol trajectories in the CCN column were calculated by a computational fluid dynamics model. These trajectories and vapour concentrations were then used as an input for the cloud parcel model to simulate mass transfer kinetics of water and semivolatiles between aerosol particles and the gas phase.

Two different questions were studied: (1) how big a fraction of semivolatiles is evaporated from particles after entering but before particle activation in the DMT-CCN counter? (2) How much can the CCN activity be increased due to condensation of semivolatiles prior to the maximum water supersaturation in the case of high semivolatile concentration in the gas phase?

Both experimental and modelling results show that the evaporation of ammonia and nitric acid from ammonium nitrate particles causes a 10 to $15 \mathrm{~nm}$ decrease to the critical particle size in supersaturations between $0.1 \%$ and $0.7 \%$. On the other hand, the modelling results also show that condensation of nitric acid or similar vapour can increase the $\mathrm{CCN}$ activity of nonvolatile aerosol particles, but a very high gas phase concentration (as compared to typical ambient conditions) would be needed. Overall, it is more likely that the
\end{abstract}

$\mathrm{CCN}$ activity of semivolatile aerosol is underestimated than overestimated in the measurements conducted in ambient conditions.

\section{Introduction}

Atmospheric aerosol particles are composed of a large variety of chemical compounds. Some of these can be considered to be nonvolatile, meaning that their vapour pressure is so low that, in practice, they are always found from the particle phase. The other group of compounds found from particles is semivolatile. Depending on conditions such as temperature and relative humidity, these compounds may exist in a gas, liquid, or solid particle phase. In the case of aqueous droplets, the partitioning between phases depends on the effective Henry's law coefficient that can be determined from liquid phase thermodynamics.

According to Köhler theory, which describes how droplet equilibrium size changes as a function of water vapour saturation ratio, the ability of a single aerosol particle to form cloud droplet at some supersaturation is mainly dependent on the amount and type of soluble material present in the particle (Köhler, 1936). Later, the Köhler theory was modified to take into account the semivolatile gases present at trace-level concentrations in the atmosphere, and they have been found to affect the cloud condensation nucleus $(\mathrm{CCN})$ activity of aerosol particles (Laaksonen et al., 1998; Kokkola 
et al., 2003a; Topping and McFiggans, 2012). Several modelling studies have shown that acidic gases, like nitric acid and hydrochloric acid, may increase the amount of solute in the liquid aerosol particles prior to cloud droplet formation and thus enhance their ability to form cloud droplets (Kulmala et al., 1993; Nenes et al., 2002; Xue and Feingold, 2004; Romakkaniemi et al., 2005). This effect is further enhanced by the presence of a gaseous base, like ammonia, that neutralizes the liquid solutions, allowing the uptake of both acid and base at a lower relative humidity (Hegg, 2000; Kokkola et al., 2003a; Romakkaniemi et al., 2005). In addition to the condensation, semivolatile gases can also evaporate from the particles, which would decrease their $\mathrm{CCN}$ activity. For example, ammonium nitrate is semivolatile and, as it is sometimes the dominant inorganic salt in the submicron aerosol, its evaporation during the sampling causes an underestimation of aerosol mass and hygroscopicity (Bergin et al., 1997; Cheng and Tsai, 1997; Zhang and McMurry, 1992; Hering and Cass, 1999; Keck and Wittmaack, 2005; Hu et al., 2011).

The CCN activity of atmospheric aerosols can be measured using the so-called $\mathrm{CCN}$ counters $(\mathrm{CCNc})$, whereby aerosol particles are exposed to known water vapour supersaturation and the activated droplets grown to micrometre sizes are counted optically. Usually, with these instruments, it is assumed that only water is condensing on particles and the solutes are nonvolatile. However, it has been shown that compounds like ammonium nitrate and ammonium chloride partly evaporate in the hygroscopic tandem differential mobility analyzer (HTDMA) system, thus decreasing their apparent hygroscopicity (e.g. Hu et al., 2011). We expect similar evaporation to take place also in the $\mathrm{CCN}$ counter (as seen already by Asa-Awuku et al., 2009), where the typical residence time before the maximum supersaturation is reached is between 2 to $4 \mathrm{~s}$. In this study, we will find out how much the possible evaporation of ammonia and nitrate decreases the CCN activity of ammonium nitrate particles when Droplet Measurement Technologies (DMT) CCN counters (Roberts and Nenes, 2005) are used.

Beyond the decrease in $\mathrm{CCN}$ activity, we determine the conditions where the condensation of a semivolatile aerosol can enhance CCN activation observed by the same instrument and whether the instrument can be used to assess the effect of nitric acid on aerosol CCN activity. Nitric acid was chosen as it is abundant in the atmosphere with concentrations up to several parts per billion, and its effect on cloud droplet formation is modelled in several publications (e.g. Kulmala et al., 1993; Laaksonen et al., 1998; Nenes et al., 2002; Romakkaniemi et al., 2005; Makkonen et al., 2012; $\mathrm{Xu}$ and Penner, 2012). $\mathrm{HNO}_{3}$ has a Henry law coefficient of $2.1 \times 10^{5} \mathrm{~mol} \mathrm{~kg}^{-1} \mathrm{~atm}^{-1}$ at room temperature. After uptake, the acid is quickly dissociated in water to form hydrogen and nitrate ions. The effective Henry's law coefficient, which controls the partitioning between the gas and liquid phase, is determined by the degree of dissociation. Thus the calculation of liquid phase thermodynamics is needed with acidic particles to determine the effective Henry's law coefficient.

\section{Methods}

In the atmosphere, the effect of semivolatile compounds on cloud droplet formation is dependent on the effective Henry's law coefficient of the condensable, number of particles present, and time available for condensation before the activation into cloud droplets. In the DMT Continuous Flow Streamwise Thermal Gradient Chamber (CFSTGC, or CCN column, Roberts and Nenes, 2005), we also have to take account the wetted walls, which act not only as a source for water vapour but also as a sink for semivolatile compounds. To take account of this, we have updated the most recent version of the CFSTGC model (Raatikainen et al., 2012) to also include semivolatile gases. With the augmented CCN counter model, we are able to calculate trajectories for aerosol particles inside the $\mathrm{CCN}$ column, and these trajectories are used to drive the air parcel model to simulate the condensation/evaporation of different compounds on/off the particles. The air parcel model (Kokkola et al., 2003b; Romakkaniemi et al., 2009) contains an aqueousphase thermodynamics module and can more accurately simulate droplet activation compared to what exists in the CFSTGC model. In the following, the methods and models used are described in more detail.

\subsection{Experiments}

The operation principle of the DMT CFSTGC is presented here briefly and presented in detail by Roberts and Nenes (2005) and Lance et al. (2006). In the instrument sheath and aerosol sample flows are introduced into the top of a cylindrical vertical tube so that sample flow will stay close to the chamber centreline. In the direction of flow, the positive thermal gradient is maintained on the wetted walls; supersaturation is formed owing to the rapid diffusion of the water, compared to heat, on the centreline and particles having lower critical supersaturation will activate to form cloud droplets. The cloud droplets that form are counted at the exit of the chamber by an optical particle counter. The supersaturation in the column will determine the smallest particle size that can activate. Usually, this size is referred to as critical (dry) particle size, and it depends on the composition of particle.

Our experimental setup consisted of an atomizer (TSI 3076), followed by a diffusion drier, Vienna type DMA (length $28 \mathrm{~cm}$, inner radius $25.0 \mathrm{~mm}$, and outer radius $33.0 \mathrm{~mm}$ ) and the DMT-CCNc described above. Particles generated in the atomizer were dried, and classified in the DMA (operating at a sheath:aerosol ratio of $10: 1$ with both sheath and excess flows set at $10 \mathrm{~L} \mathrm{~min}^{-1}$ ). To minimize 
volatilization of the dried particles, the distance between DMA and CCN counter was kept as short as possible $(\sim 0.3 \mathrm{~s})$. Critical dry size in different supersaturations was determined by changing the particle size with DMA and keeping the supersaturation constant in the $\mathrm{CCN}$ column. Activation curves were corrected to take into account multiple charging in the DMA, and the critical dry size was determined as a size where $50 \%$ of particles activated (diameter commonly referred to as D50). This was repeated for supersaturations between 0.1 and $0.8 \%$.

\subsection{CCNc model}

The CCN counter model calculates flow velocity fields and distributions of temperature, pressure, water vapour and semivolatile gases in the CCN column using known boundary conditions such as sheath and sample flow rates, column top temperature, sample flow pressure and calibrated maximum supersaturation. Aerosol trajectories are calculated from the velocity fields, and these, with related gas phase concentrations and temperature profiles, are saved to be used in the cloud parcel model. The current model version is based on the original instrument model of Lathem and Nenes (2011), later updated by Raatikainen et al. (2012). An additional section similar to that of water vapour was added to the model for the semivolatile gas, which is here either ammonia or nitric acid. The only sources for the semivolatile gases are sheath and sample flows at the inlet, and the wet chamber walls are a sink. Simple calculations can be used to show that the water flow rate at the chamber wall is large enough to absorb all the semivolatile gas without significant changes in the surface pressure. Similarly, when using moderate aerosol concentrations $\left(<3000 \mathrm{~cm}^{-3}\right)$, aerosols are a negligible sink or source for the semivolatile gases, as will be shown later. When these two assumptions hold, droplet growth can be examined in the detailed cloud parcel model using aerosol trajectories, vapour concentrations and temperature from the $\mathrm{CCNc}$ model.

\subsection{Cloud parcel model}

To simulate the uptake of water and semivolatile gases on aerosol particles, we use the cloud parcel model. The model has been described elsewhere (Kokkola et al., 2003b), and it has been used in several aerosol cloud interaction studies (e.g. Romakkaniemi et al., 2005, 2011, 2012). Instead of running the model adiabatically, as is usually done, the ambient temperature and gas phase concentrations are fed to the model as trajectories in a similar manner as done in Romakkaniemi et al. (2009), where the same model was used with trajectories from Large Eddy Model simulations. We assumed that the mass transfer between particles and gas does not affect the gas phase concentration. It was also verified that this assumption does not affect the results. In the model, the differential equations are solved using an ordinary differential equation solver DLSODE (www.netlib. org), which solves initial-value problems for stiff or non-stiff ordinary differential equations using backward differentiation formulae. The liquid phase thermodynamics needed for the calculation of equilibrium vapour pressures is based on a modified version of aerosol equilibrium code EQUISOLV II (Jacobson, 1999).

In the analysis of modelling results, we concentrate on two different applications of the model: the ability of nitric acid to condense on aerosol particles prior to activation into cloud droplets and the possibility of evaporation of semivolatile gases before the activation takes place. The simulations are carried out in such a way that the aerosol is equilibrated with respect to water in the inlet (no mass transfer of semivolatiles), and, as soon as the aerosol arrives in the CCN column and deliquescence $\mathrm{RH}$ is achieved, the mass transfer of semivolatiles and water vapour is allowed.

\section{Results}

First, we study and compare the mass transfer timescales for $\mathrm{HNO}_{3}$. In the $\mathrm{CCN}$ column, the supersaturation is usually reached within 2-3 s from entrance into the column. As the diffusion coefficient used for $\mathrm{HNO}_{3}$ is $1.51 \times 10^{-5} \mathrm{~m}^{2} \mathrm{~s}^{-1}$ at $298 \mathrm{~K}$ (Kokkola, 2003), mass transfer to the walls is rapid compared to time needed for droplet activation. Figure 1 shows an example of $\mathrm{HNO}_{3}$ concentration when the $\mathrm{HNO}_{3}$ concentration is initially $10 \mathrm{ppb}$ in both sample and sheath air. In the upper panel, the concentration is presented for the column half cross section and in the lower panel at the centreline, where the aerosol sample is assumed to stay. It can be seen that, before reaching supersaturation, more than $90 \%$ of $\mathrm{HNO}_{3}$ is already lost to the walls. Thus, it is clear that a high amount of $\mathrm{HNO}_{3}$ is needed in the gas phase to see a notable increase in aerosol mass and CCN activity. On the other hand, fast depletion of semivolatiles from gas phase will also enhance the evaporation of these compounds from particles.

\subsection{Ammonium nitrate evaporation}

To evaluate our model performance, we studied how ammonium nitrate evaporates from particles in the CCN column. Here, we assume that ammonia and nitric acid have an initial concentration of $100 \mathrm{ppt}$ at the top of the $\mathrm{CCN}$ column, but, after that, both gases can diffuse to the wet column walls. The dry sample aerosol is assumed to be nonvolatile, but as soon as the aerosol deliquesces after arriving in the $\mathrm{CCN}$ column, both ammonia and nitric acid are able to evaporate.

In Fig. 2, an example of particle evaporation is shown with particles composed initially of 90 mass $\%$ of ammonium nitrate and 10 mass $\%$ of ammonium sulfate. As can be expected, the evaporation of $\mathrm{HNO}_{3}$ and $\mathrm{NH}_{3}$ (and decrease in the effective dry size) is fastest after the introduction of particles into the column. Due to water condensation the droplets 


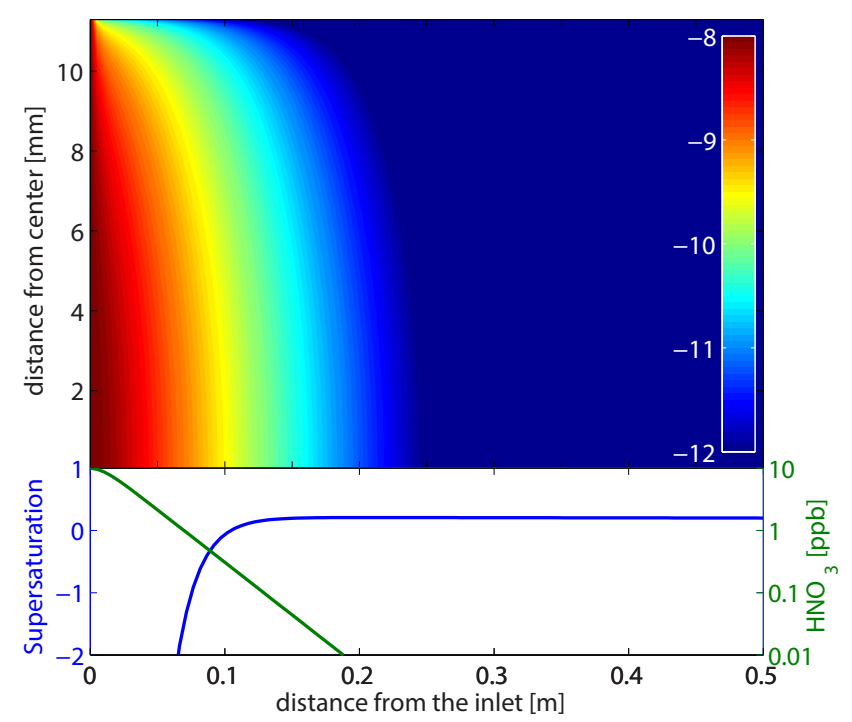

Figure 1. Nitric acid concentration in the column. The air flow is from left to right and the sample flow is within $2.3 \mathrm{~mm}$ of the centre.

are more diluted later in the column, and this decreases the evaporation. The mass fraction evaporated before the activation is dependent on the size of the original particle. In the example, the smallest particle has already lost $58 \%$ of the initial dry volume before the water vapour saturation ratio reaches unity ( $0.1 \mathrm{~m}$ from the inlet in the $\mathrm{CCN}$ column) and $85 \%$ before maximum supersaturation $(0.2 \mathrm{~m}$ from the inlet). For the smallest size still activating, the corresponding values are 30 and $36 \%$. However, as can be seen from Fig. 2, the particles continue to lose matter even after supersaturation is reached.

How much semivolatiles evaporate (and thus decrease the measured hygroscopicity) before the column maximum supersaturation is achieved depends on the time (location of the maximum supersaturation), size, concentration of particles and gas phase concentration. We performed laboratory experiments using a DMT CCN counter (Roberts and Nenes, 2005; Lance et al., 2006). For the experiments, ammonium nitrate particles were created and their critical dry diameters were measured as a function of supersaturation. In the experiments, the aerosol concentration was $\sim 500 \mathrm{~cm}^{-3}$ after the DMA. We also performed simulations using $100 \mathrm{ppt}$ concentration of both gases in the sample and sheath air, and changing the supersaturation. The $100 \mathrm{ppt}$ is chosen as it is a reasonable concentration for background air, and likely to be of the same order as the concentration in the experiments conducted. Also, the simulation results are not very sensitive to changes in assumed concentration as $100 \mathrm{ppt}$ concentration is well below the equilibrium value. Figure 3 shows both the experimental and simulated (with and without evaporation) critical particle dry sizes as a function of supersaturation. The red curve would give expected D50 if there were no evaporation of nitric acid and, in the case of the blue curve,

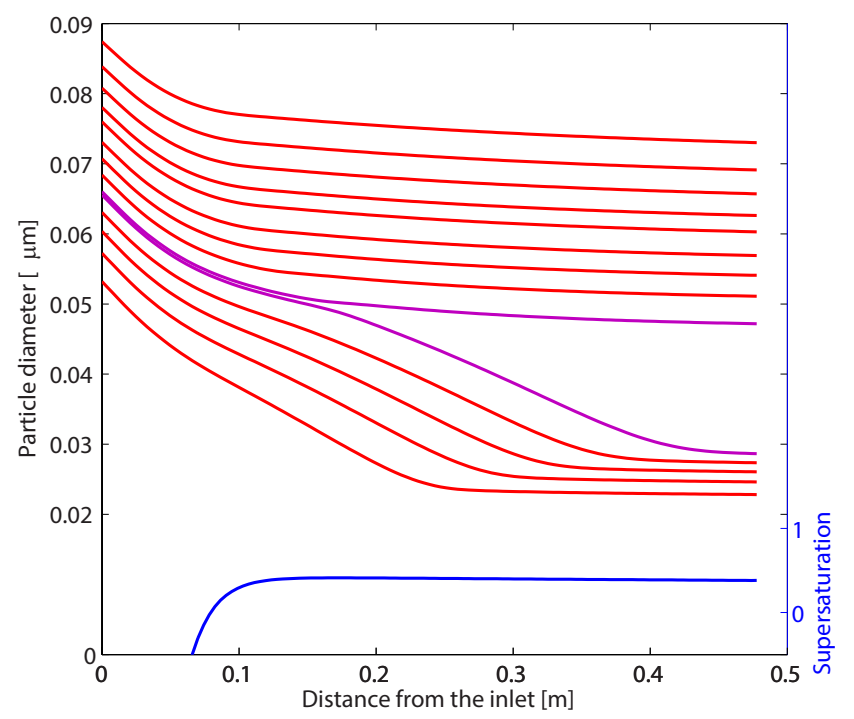

Figure 2. Effective dry size of particles composed of 90 mass $\%$ of ammonium nitrate and 10 mass $\%$ of ammonium sulfate as a function of position in the CCN column. Particles closest to the activation size are marked with magenta. The supersaturation is represented by a blue line.

the evaporation is taken into account. The simulation results show that the evaporation in the CCN column leads to a 10 to $15 \mathrm{~nm}$ reduction in the effective dry size with particles having initial size between 40 and $120 \mathrm{~nm}$. Thus, it should be detectable for all supersaturations, but the effect is relatively stronger in high supersaturation where particle size is smaller. This happens mainly because small particles are able to follow their equilibrium size more closely than the larger ones, as their surface-to-volume ratio is higher, and thus they lose ammonia and nitrate more quickly. The laboratory experiments are in good agreement with the simulations in accounting for ammonium nitrate evaporation. The model overestimates the change in effective dry size due to evaporation on average by $1.9 \mathrm{~nm}$, i.e. a $16 \%$ relative difference.

\subsection{Condensation of nitric acid}

Next, we study with the model how the condensation of nitric acid from gas phase could enhance particle activation. In Fig. $4 a$, the change in critical dry diameter is presented as a function of $\mathrm{HNO}_{3}$ gas phase concentration for nine different aerosol compositions. Both sample and sheath air are assumed to have the same gas phase concentration, and the maximum supersaturation in the counter is $0.2 \%$. Ammonia is also assumed to be nonvolatile; this is justified by the large excess of $\mathrm{HNO}_{3}$. Different red lines show how the ratio of soluble to insoluble matter affects the $\mathrm{HNO}_{3}$ potential by considering ammonium sulfate as soluble with mass fractions of 1, 10,50 and $100 \%$, with the rest being insoluble. As can be seen, the nitric acid effect is practically independent 


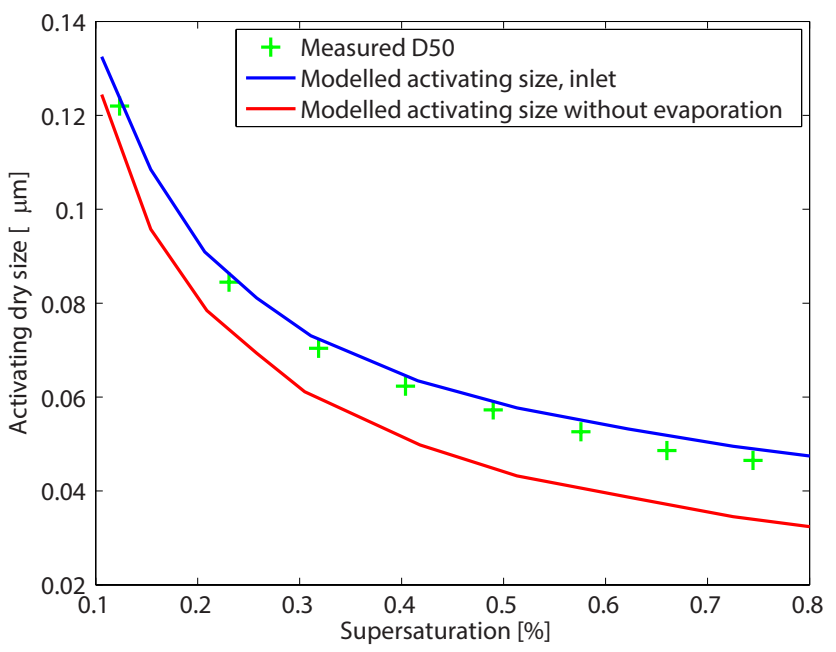

Figure 3. Size of activating particles in different supersaturations when the evaporation of nitric acid and ammonia is not taken into account (red curve) and when the evaporation is taken into account in the model. The green crosses are measured critical particle dry sizes for ammonium nitrate in different supersaturations.

of the soluble mass fraction. Also, the effect becomes notable when the concentration at the top of the CCN column is a few parts per billion, but $\sim 13 \mathrm{ppb}$ concentration is needed to get over a $10 \%$ reduction in critical dry diameter. To examine the $\mathrm{HNO}_{3}$ effect on measured aerosol hygroscopicity, we can use the equation

$\kappa=\frac{4 A^{3}}{27 D_{\mathrm{c}}^{3} \ln ^{2} S_{\mathrm{c}}}, A=\frac{4 \sigma_{\mathrm{w}} M_{\mathrm{w}}}{\mathrm{RT} \rho_{\mathrm{w}}}$,

where $D_{\mathrm{c}}$ is the critical dry diameter, $S_{\mathrm{c}}$ is the saturation ratio applied in the CCNc, $\sigma_{\mathrm{w}}$ is surface tension, $M_{\mathrm{w}}$ is mole mass, and $\rho_{\mathrm{w}}$ is water density (Petters and Kreidenweis, 2007). In the equation, the critical dry diameter has a power of -3 , and thus only a $3 \%$ decrease in the critical dry diameter will lead to $\sim 10 \%$ overestimation in the hygroscopicity. As can be seen from Fig. 4 b, only 3 ppb of $\mathrm{HNO}_{3}$ is needed to produce such overestimation in the case of ammonium sulfate and $5 \mathrm{ppb}$ in the case of ideal model aerosol that has no interaction with the condensed acid. For comparison, the theoretical calculation based on Laaksonen et al. (1998) gives a $35 \%$ reduction in critical dry size of ammonium sulfate with $1 \mathrm{ppb}$ of nitric acid, and compared to this the effect seen in the CCN counter is much smaller. This is because $97 \%$ of the nitric acid (Fig. 1) is already condensed on the walls before supersaturation is achieved in the centreline of the CCN column. Thus, for using the DMT CCN counter to quantify the $\mathrm{CCN}$ activity enhancement due to semivolatile condensation in atmospheric conditions, a very careful validation of gas phase concentration is needed. Also, the possibility of using water flow on the walls as a source of semivolatile instead of sample and sheath air should be studied.
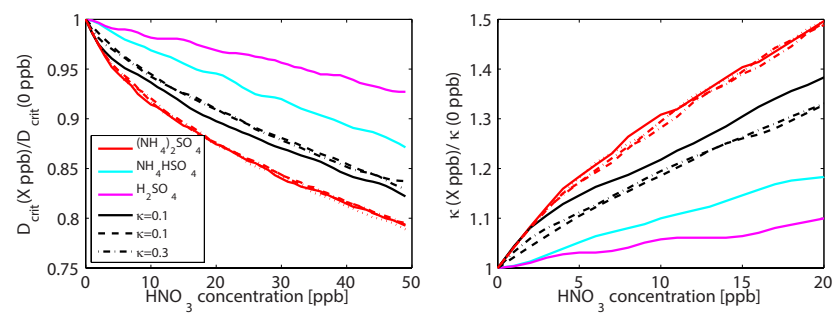

Figure 4. (a) Relative change in the critical dry diameter (at the supersaturation of $0.2 \%$ ) as a function of nitric acid concentration for aerosol having nine different compositions. Critical dry diameters for the case modelled without nitric acid are 81, 106, 184 and $364 \mathrm{~nm}$ for the four different ammonium sulfate mass fractions and $80,77,148,117$ and $102 \mathrm{~nm}$ for the other species presented in the legend. (b) Relative change in estimated aerosol hygroscopicity.

For the amount of condensed $\mathrm{HNO}_{3}$, aerosol acidity is a more important factor than the mass fraction of soluble compounds. The Henry's law coefficient gives the amount of aqueous $\mathrm{HNO}_{3}$, which depends on the mass fraction of soluble compounds. However, most of the aqueous $\mathrm{HNO}_{3}$ is quickly dissociated into hydrogen and nitrate ions. The degree of dissociation, which eventually controls the total amount of acid dissolved in the aqueous phase, is influenced by other ions present. The uptake of nitric acid is rapid after the deliquescence of neutral ammonium sulfate leading to a strong increase in measured aerosol hygroscopicity. In the case of more acidic aerosols such as ammonium bisulfate and sulfuric acid, the uptake of $\mathrm{HNO}_{3}$ is postponed to a higher relative humidity. Also, the increase in measured aerosol hygroscopicity is smaller than in the case of ammonium sulfate. This is because with ammonium sulfate the increase in acidity caused by $\mathrm{HNO}_{3}$ dissociation is buffered by the change in equilibrium concentration between sulfate and bisulfate ions. If there is no interaction between the condensed $\mathrm{HNO}_{3}$ and the particle's original components, condensed $\mathrm{HNO}_{3}$ causes a smaller increase in the hygroscopicity than for ammonium sulfate. We studied this in more detail by introducing an ideal-model aerosol and varying its hygroscopicity in terms of $\kappa$. As can be seen from Fig. 4b, the relative effect of $\mathrm{HNO}_{3}$ condensation on measured hygroscopicity is not dependent on the original hygroscopicity. With other aerosol components, like $\mathrm{NaCl}$, the $\mathrm{Cl}^{-}$is replaced by $\mathrm{NO}_{3}^{-}$leading to evaporation of $\mathrm{HCl}$ (e.g. Gard et al., 1998). This could cause the measured hygroscopicity to be less than $\mathrm{NaCl}$ hygroscopicity. An even more complex situation could arise with dust containing $\mathrm{CaCO}_{3}$, where $\mathrm{CO}_{3}^{2-}$ could be replaced by $2 \mathrm{NO}_{3}^{-}$leading to very hygroscopic $\mathrm{Ca}\left(\mathrm{NO}_{3}\right)_{2}$ (see e.g. Goodmann et al., 2000).

In the simulations, we have assumed a quite low aerosol number concentration $\left(100 \mathrm{~cm}^{-3}\right)$, and the amount of $\mathrm{HNO}_{3}$ in the single particle at the time of maximum supersaturation is between 0.05 and $0.15 \%$ of the amount in the gas phase. In Fig. 5, the partitioning and change in the particle 


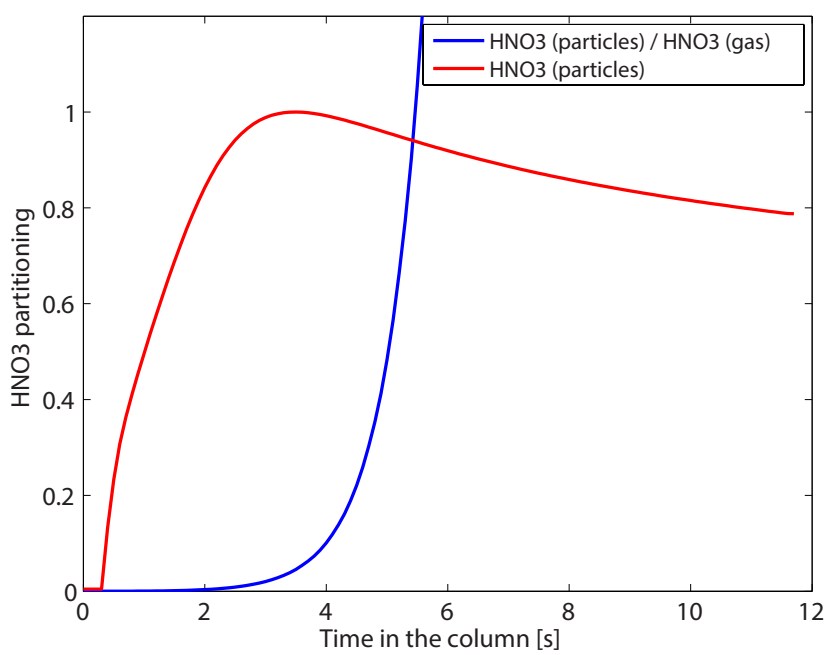

Figure 5. Partitioning of $\mathrm{HNO}_{3}$ between the gas and particle phase (blue curve) and total $\mathrm{HNO}_{3}$ concentration in the particles (scaled to give 1 as a maximum) in the case of $0.2 \%$ supersaturation and ammonium sulfate aerosol.

phase concentration is presented in more detail in the case of ammonium sulfate. It can be seen that the maximum $\mathrm{HNO}_{3}$ concentration in the particles is actually achieved before the maximum supersaturation (3.5 and $4.3 \mathrm{~s}$ in the Fig. 5) and, at that time, the amount in the particles is only $4 \%$ of total amount. Thus, the system is not sensitive to particle number concentration with moderate concentrations. However, care must be taken if the results presented are used with high aerosol loading $\left(>3000 \mathrm{~cm}^{-3}\right)$, and to get reliable results in such conditions, a more accurate thermodynamic model should be coupled to the CFSTGC model directly. With a higher supersaturation, the fraction of semivolatiles partitioned to particles is even smaller as supersaturation is reached earlier in the column and particles are of smaller size. For example, with $0.8 \%$ supersaturation, the amount of $\mathrm{HNO}_{3}$ partitioned to a single particle is between 0.007 and $0.02 \%$ of the amount in the gas phase depending on the particle's composition.

Another potential parameter affecting the increase in $\mathrm{CCN}$ potential due to semivolatiles is the water vapour supersaturation. This is shown in Fig. 6, where the change in aerosol hygroscopicity due to $10 \mathrm{ppb}$ of $\mathrm{HNO}_{3}$ is presented as a function of supersaturation for two different types of particles. It can be seen that the nitric acid effect is highest close to $0.2 \%$ supersaturation, decreasing slightly towards higher supersaturations. The behaviour is the same for both ideal-model particles $(\kappa=0.3)$ and ammonium sulfate particles.

\subsection{The effect of semivolatiles on CCN activity}

In the simulations presented, we have used nitric acid as an example of semivolatile compound that can partition from vapour phase to aerosol particles. The effect seen on particles' $\mathrm{CCN}$ activity is naturally dependent on the

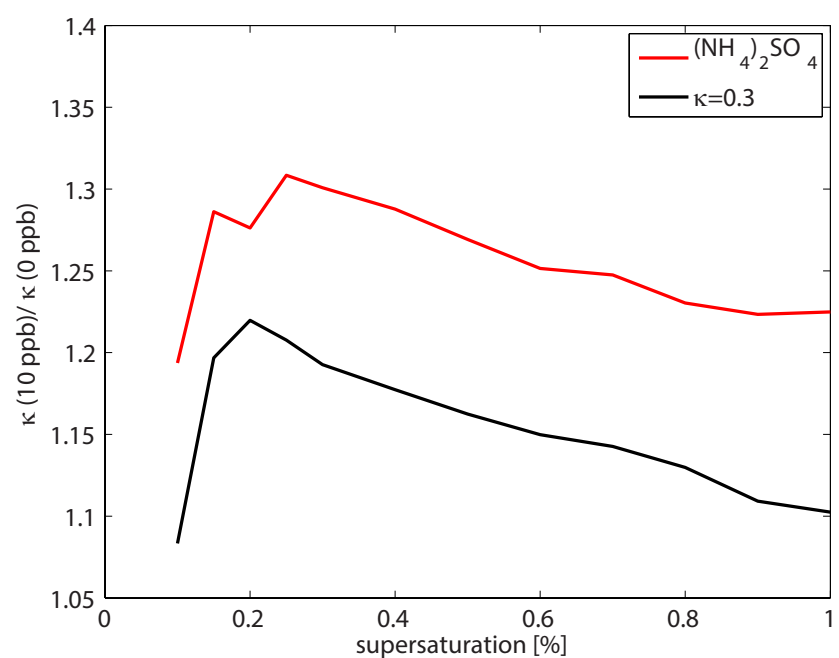

Figure 6. Change in modelled aerosol hygroscopicity due to $10 \mathrm{ppb}$ of $\mathrm{HNO}_{3}$ as a function of supersaturation for aerosol composed of ammonium sulfate and model aerosol with the hygroscopicity $\kappa$ of 0.3 .

compounds, and, especially, the effective Henry's law coefficient. With a lower coefficient, the uptake is postponed and, thus, the enhancement in the CCN activity will get smaller. The opposite will happen when evaporation is considered, and CCN activity will be underestimated. We did simulations by a hypothetical compound with physical properties of the nitric acid molecule and effective Henry's law partitioning coefficient between $1 \times 10^{5} \mathrm{~mol} \mathrm{~kg}^{-1} \mathrm{~atm}^{-1}$ and $1 \times 10^{11} \mathrm{~mol} \mathrm{~kg}^{-1} \mathrm{~atm}^{-1}$. The high value represents nonvolatile material that evaporates too slowly inside the $\mathrm{CCN}$ column to affect the activation of particles and the lower value represents semivolatile aerosol that has higher volatility than that of nitric acid. It turns out that the evaporation will become efficient when the coefficient is smaller than $\sim 5 \times 10^{9} \mathrm{~mol} \mathrm{~kg}^{-1} \mathrm{~atm}^{-1}$. On the other hand the condensation will play a role after the coefficient exceeds $\sim 2 \times$ $10^{7} \mathrm{~mol} \mathrm{~kg}^{-1} \mathrm{~atm}^{-1}$. When the effective Henry's law coefficient is between these values particles may grow or shrink based on the chemical composition and gas phase concentration. In the case of several semivolatile compounds the partitioning of a single compound will be similar as in the case of only one compound. However, the role of liquid phase thermodynamics is even more important as the effective Henry's law coefficient of a single compound is affected by all molecules in the solution and thus evaporation/condensation of one compound will affect other compounds also.

Also, the diffusion coefficient will play some role, and, with larger molecules, the diffusion to walls is slower and thus semivolatiles have more time to condense on particles. However, smaller diffusion coefficient will slow condensation on the particles, and, thus, the total effect is minor compared to that of the Henry's law coefficient. 


\section{Conclusions}

In this study, we have constructed a model that can be used to study how semivolatile water-soluble compounds, like nitric acid and ammonia, can affect the CCN potential of aerosol particles by condensing or evaporating of the liquid particles/droplets in the CCN counter. The existing CCN model (designed for the DMT CCN counter) was modified to include diffusion of semivolatile gases from sample and sheath flows to chamber walls. The CCN model was used to produce aerosol trajectories inside the $\mathrm{CCN}$ column, which were later used as an input for the air parcel model to simulate growth of aerosol particles to cloud droplet sizes.

It is shown that care must be taken when the results from $\mathrm{CCN}$ counter experiments are used to study the CCN potential of aerosol particles. The semivolatile concentrations needed to increase the $\mathrm{CCN}$ potential of aerosol particles are high, but such that they are present in the atmosphere in highly polluted conditions, and inclusion of several other semivolatiles, many of them organics, could affect the results considerably (Topping and McFiggans, 2012; Topping et al., 2013). This is especially important in laboratory studies, where the concentrations used might be tenfold higher than those found in the atmosphere. However, typical conditions in the atmosphere are such that the concentrations of semivolatile gases are too low to considerably increase the $\mathrm{CCN}$ potential and thus affect the $\mathrm{CCN}$ studies. In addition, diffusional losses of semivolatile gases within the measurement system are likely to decrease concentrations before actual measurements. For these reasons, it is also difficult to use a DMT CCN counter to experimentally quantify the previously modelled enhancement of particles $\mathrm{CCN}$ activity due to semivolatile condensation prior to cloud droplet formation in the atmosphere.

The more important effect comes from the evaporation of some semivolatiles before particles reach cloud droplet sizes. First of all, it is shown both experimentally and by using model simulations that ammonium nitrate, which is one of the most common inorganic salts in ambient aerosols, evaporates in the $\mathrm{CCN}$ counter causing a bias in the observed $\mathrm{CCN}$ activity. Similar observations have been made with other experimental techniques and by using models, but to our knowledge this is the first study quantifying the evaporation bias for a DMT CCN counter. Although we have focused on ammonium nitrate, a significant fraction of organic species of ambient aerosols are semivolatile. These were not included in our study, because these species can evaporate already from the solid particles before reaching the $\mathrm{CCN}$ counter. Also, the high temperature inside the CCN column increases volatility and the rate of mass transfer when compared to ambient temperature; thus, part of the semivolatiles might be evaporating before cloud droplet activation (e.g. Asa-Awuku et al., 2009; Tang et al., 2014). As a result, the effect of evaporation depends strongly on the measurement setup. Also, in the $\mathrm{CCN}$ counter, wet chamber walls are a sink for water-soluble semivolatiles, which means that the gases removed from the system are not participating in the cloud droplet formation as in the ambient conditions.

Acknowledgements. This research has been supported by the strategic funding of the University of Eastern Finland, by the Academy of Finland Centre of Excellence Program (project no. 1118615) and by the Academy of Finland Research Fellow project (no. 267514). Antti Jaatinen was supported by the Kone Foundation. The Finnish Cultural Foundation is also acknowledged for financial support.

Edited by: H. Herrmann

\section{References}

Asa-Awuku, A., Engelhart, G. J., Lee, B. H., Pandis, S. N., and Nenes, A.: Relating CCN activity, volatility, and droplet growth kinetics of $\beta$-caryophyllene secondary organic aerosol, Atmos. Chem. Phys., 9, 795-812, doi:10.5194/acp-9-795-2009, 2009.

Bergin, M. H., Ogren, J. A., Schwartz, S. E., and McInne, L. M.: Evaporation of Ammonium Nitrate Aerosol in a Heated Nephelometer: Implications for Field Measurements, Environ. Sci Technol., 31, 2878-2883, 1997.

Cheng, Y.-H. and Tsai, C.-J.: Evaporation loss of ammonium nitrate particles during filter sampling, J. Aerosol Sci., 28, 1553-1567, 1997.

Gard, E. E., Kleeman, M. J., Gross, D. S., Hughes, L. S., Allen, J. O., Morrical, B. D., Fergenson, D. P., Dienes, T., Gälli, M. E., Johnson, R. J., Cass, G. R., and Prather, K. A.: Direct observation of heterogeneous chemistry in the atmosphere, Science, 279 , 1184-1187, 1998

Goodman, A. L., Underwood, G. M., and Grassian, V. H.: A laboratory study of the heterogeneous reaction of nitric acid on calcium carbonate particles, J. Geophys. Res., 105, 29053-29064, doi:10.1029/2000JD900396, 2000.

Hegg, D. A.: Impact of gas-phase $\mathrm{HNO}_{3}$ and $\mathrm{NH}_{3}$ on microphysical processes in atmospheric clouds, Geophys. Res. Lett., 27, 22012204, 2000.

Hering, S. and Cass, G.: The Magnitude of Bias in the Measurement of $\mathrm{PM}_{2.5}$ Arising from Volatilization of Particulate Nitrate from Teflon Filters, J. Air Waste Manage., 49, 725-733, 1999.

Hu, D., Chen, J., Ye, X., Li, L., and Yang, X.: Hygroscopicity and evaporation of ammonium chloride and ammonium nitrate: Relative humidity and size effects on the growth factor, Atmos. Environ, 45, 2349-2355, doi:10.1016/j.atmosenv.2011.02.024, 2011.

Jacobson, M. Z.: Studying the effects of calcium and magnesium on size-distributed nitrate and ammonium with EQUISOLV II, Atmos. Environ., 33, 3635-3649, 1999.

Keck, L. and Wittmaack, K.: Effect of filter type and temperature on volatilisation losses from ammonium salts in aerosol matter, Atmos. Environ., 39, 4093-4100, 2005.

Köhler, H.: The nucleus in and the growth of hygroscopic droplets, Trans. Farad. Soc., 32, 1152-1161, 1936.

Kokkola, H.: Model studies on the evolution of fogs and clouds in the presence of semi-volatile gases, Ph.D. thesis, Report Series in Aerosol Science, Finnish Association for Aerosol Research, Helsinki, 106 pp., 2003. 
Kokkola, H., Romakkaniemi, S., and Laaksonen, A.: Köhler theory for a polydisperse droplet population in the presence of a soluble trace gas, and an application to stratospheric STS droplet growth, Atmos. Chem. Phys., 3, 2139-2146, doi:10.5194/acp-32139-2003, 2003a.

Kokkola, H., Romakkaniemi, S., Kulmala, M., and Laaksonen, A.: A one-dimensional cloud model including trace gas condensation and sulfate chemistry, Boreal Environ. Res., 8, 413-424, 2003 b.

Kulmala, M., Laaksonen, A., Korhonen, P., Vesala, T., Ahonen, T., and Barrett, J. C.: The effect of atmospheric nitric acid vapor on CCN activation, J. Geophys. Res.-Atmos., 98, 22949-22958, 1993.

Laaksonen, A., Korhonen, P., Kulmala, M., and Charlson, R. J.: Modification of the Köhler equation to include soluble trace gases and slightly soluble substances, J. Atmos. Sci., 55, 853$862,1998$.

Lance, S., Medina, J., Smith, J. N., and Nenes, A.: Mapping the Operation of the DMT Continuous Flow CCN Counter, Aerosol. Sci. Tech., 40, 242-254, doi:10.1080/02786820500543290, 2006.

Lathem, T. L. and Nenes, A.: Water vapor depletion in the DMT Continuous Flow CCN Chamber: effects on supersaturation and droplet growth, Aerosol. Sci. Tech., 45, 604-615, doi:10.1080/02786826.2010.551146, 2011.

Makkonen, R., Romakkaniemi, S., Kokkola, H., Stier, P., Räisänen, P., Rast, S., Feichter, J., Kulmala, M., and Laaksonen, A.: Brightening of the global cloud field by nitric acid and the associated radiative forcing, Atmos. Chem. Phys., 12, 7625-7633, doi:10.5194/acp-12-7625-2012, 2012.

Nenes, A., Charlson, R. J., Facchini, M. C., Kulmala, M., Laaksonen, A., and Seinfeld, J. H.: Can chemical effects on cloud drop number rival the first indirect effect?, Geophys. Res. Lett., 29, 1848, doi:10.1029/2002GL015295, 2002.

Petters, M. D. and Kreidenweis, S. M.: A single parameter representation of hygroscopic growth and cloud condensation nucleus activity, Atmos. Chem. Phys., 7, 1961-1971, doi:10.5194/acp-71961-2007, 2007.

Raatikainen, T., Moore, R. H., Lathem, T. L., and Nenes, A.: A coupled observation - modeling approach for studying activation kinetics from measurements of CCN activity, Atmos. Chem. Phys., 12, 4227-4243, doi:10.5194/acp-12-4227-2012, 2012.

Roberts, G. C. and Nenes, A.: A Continuous-Flow Streamwise Thermal-Gradient CCN Chamber for Atmospheric Measurements, Aerosol Sci. Tech., 39, 206-221, doi:10.1080/027868290913988, 2005.
Romakkaniemi, S., Kokkola, H., and Laaksonen, A.: The soluble trace gas effect on $\mathrm{CCN}$ activation: inuence of initial equilibration on cloud model results, J. Geophys. Res.-Atmos., 110, D15202, doi:10.1029/2004JD005364, 2005.

Romakkaniemi, S., McFiggans, G., Bower, K. N., Brown, P., Coe, H., and Choularton, T. W.: A comparison between trajectory ensemble and adiabatic parcel modelled cloud properties and evaluation against airborne measurements, J. Geophys. Res., 114, D06214, doi:10.1029/2008JD011286, 2009.

Romakkaniemi, S., Kokkola, H., Smith, J. N., Prisle, N. L., Schwier, A. N., McNeill, V. F., and Laaksonen, A.: Partitioning of semivolatile surface active compounds between bulk, surface and gas phase, Geophys. Res. Lett., 38, L03807, doi:10.1029/2010GL046147, 2011.

Romakkaniemi, S., Arola, A., Kokkola, H., Birmili, W., Tuch, Th., Kerminen, V. M., Räisänen, P., Smith, J., Korhonen, H., and Laaksonen, A.: Effect of aerosol size distribution on AOD, $\mathrm{CCN}$ and cloud droplet concentration: a case study from Erfurt and Melpitz, Germany, J. Geophys. Res., 17, D07202, doi:10.1029/2011JD017091, 2012.

Tang, X., Price, D., Praske, E., Vu, D., Purvis-Roberts, K., Silva, P. J., Cocker III, D. R., and Asa-Awuku, A.: CCN activity of aliphatic amine secondary aerosol, Atmos. Chem. Phys. Discuss., 14, 31-56, doi:10.5194/acpd-14-31-2014, 2014.

Topping, D. O. and McFiggans, G.: Tight coupling of particle size, number and composition in atmospheric cloud droplet activation, Atmos. Chem. Phys., 12, 3253-3260, doi:10.5194/acp-12-32532012, 2012.

Topping, D. O., Connolly, P., and McFiggans, G.: Cloud droplet number enhanced by co-condensation of organic vapours, Nat. Geosci., 6, 443-446, doi:10.1038/ngeo1809, 2013.

$\mathrm{Xu}, \mathrm{L}$. and Penner, J. E.: Global simulations of nitrate and ammonium aerosols and their radiative effects, Atmos. Chem. Phys., 12, 9479-9504, doi:10.5194/acp-12-9479-2012, 2012.

Xue, H. and Feingold, G.: A modeling study of the effect of nitric acid on cloud properties, J. Geophys. Res., 109, D18204, doi:10.1029/2004JD004750, 2004.

Zhang, X. and McMurry, P. H.: Evaporative losses of fine particulate nitrates during sampling, Atmos. Environ. A-Gen., 26, 33053312, 1992. 